\title{
An environmentally friendly ball milling process for recovery of valuable metals from e-waste scraps
}

\author{
Zhi-Yuan Zhang a,b,*, Fu-Shen Zhang a,b, TianQi Yao ${ }^{c}$

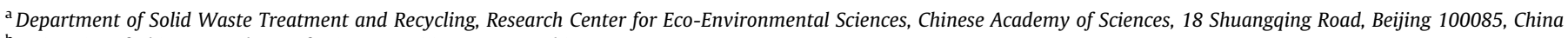 \\ ${ }^{\mathrm{b}}$ University of Chinese Academy of Sciences, Beijing 100039, China \\ ' Nankai University, No. 94 Weijin Road, Tianjin 300191, China
}

\section{A R T I C L E I N F O}

\section{Article history:}

Received 30 March 2017

Revised 12 July 2017

Accepted 17 July 2017

Available online 23 July 2017

\section{Keywords:}

Ball milling

E-waste

Metal recovery

Mechanochemical process

\begin{abstract}
A B S T R A C T
The present study reports a mechanochemical (MC) process for effective recovery of copper $(\mathrm{Cu})$ and precious metals (i.e. $\mathrm{Pd}$ and $\mathrm{Ag}$ ) from e-waste scraps. Results indicated that the mixture of $\mathrm{K}_{2} \mathrm{~S}_{2} \mathrm{O}_{8}$ and $\mathrm{NaCl}$ (abbreviated as $\mathrm{K}_{2} \mathrm{~S}_{2} \mathrm{O}_{8} / \mathrm{NaCl}$ hereafter) was the most effective co-milling reagents in terms of high recovery rate. After co-milling with $\mathrm{K}_{2} \mathrm{~S}_{2} \mathrm{O}_{8} / \mathrm{NaCl}$, soluble metallic compounds were produced and consequently benefit the subsequent leaching process. 99.9\% of $\mathrm{Cu}$ and $95.5 \%$ of $\mathrm{Pd}$ in the e-waste particles could be recovered in $0.5 \mathrm{~mol} / \mathrm{L}$ diluted $\mathrm{HCl}$ in $15 \mathrm{~min}$. Ag was concentrated in the leaching residue as $\mathrm{AgCl}$ and then recovered in $1 \mathrm{~mol} / \mathrm{L} \mathrm{NH}_{3}$ solution. XRD and XPS analysis indicated that elemental metals in the raw materials were transformed into their corresponding oxidation state during ball milling process at low temperature, implying that solid-solid phase reactions is the reaction mechanism. Based on the results and thermodynamic parameters of the probable reactions, possible reaction pathways during ball milling were proposed. Suggestion on category of e-waste for ball milling process was put forward according to the experiment results. The designed metal recovery process of this study has the advantages of highly recovery rate and quick leaching speed. Thus, this study offers a promising and environmentally friendly method for recovering valuable metals from e-waste.
\end{abstract}

(c) 2017 Elsevier Ltd. All rights reserved.

\section{Introduction}

Recycling of e-waste is an important subject not only from the point of waste treatment but also from the recovery aspect of valuable materials (Cui and Zhang, 2008; Oguchi et al., 2011). Among the resources in e-waste, metals contribute to more than $95 \%$ of the materials' market value (Chancerel et al., 2009). Hence, the recovery of valuable metals is the inherent motive in e-waste disposal.

In the past decades, many techniques for recovering valuable metals from e-waste have been developed such as gravity separation, magnetic separation and electrostatic separation, (Kaya, 2016; Veit et al., 2005), synthesis of $\mathrm{CuCl}$ with e-waste(Zhang and Zhang, 2013), separation of PCBs with organic solvent method (Zhu et al., 2013), cyanide and non-cyanide lixiviants leaching (Akcil et al., 2015) methods, ammonium persulfate leaching (Alzate et al., 2016), bioeaching methods (Işıldar et al., 2016;

\footnotetext{
* Corresponding author at: Department of Solid Waste Treatment and Recycling, Research Center for Eco-Environmental Sciences, Chinese Academy of Sciences, 18 Shuangqing Road, Beijing 100085, China.

E-mail address: zhangzy@rcees.ac.cn (Z.-Y. Zhang).
}

Karwowska et al., 2014) or a combination of these approaches (Kim et al., 2011; Xiu et al., 2013). Among those methods, hydrometallurgical methods are more accurate, predictable and controllable than others. Therefore, hydrometallurgical techniquesare most active in the research of valuable metals recovery from electronic scraps in the past two decades. However, traditional hydrometallurgical methods are acid dependent, time-consuming and inefficient for simultaneously recovery of precious metals. Remarkably, large amount of corrosive or toxic reagents, such as aqua regia, nitric acid, cyanide and halide, are consumed, producing large quantities of toxic and corrosive fumes or solution (Chagnes et al., 2016; Cui and Zhang, 2008). Therefore, it is necessary to seek more environmentally friendly method for the recovery of valuable metals from e-wastes.

Recently, mechanochemical (MC) technology has been widely applied in extractive metallurgy, waste treatment, crystal engineering and material engineering (Chai et al., 2013; Guo et al., 2010; Plescia et al., 2003). In MC treatment, repeated fracturing and cold welding occurred to the reacting particles during collisions when the respective wastes or materials are milled with reactive chemicals in a ball mill (Zhang et al., 2013). Thus, MC solid phase reactions that cannot occur normally due to separation of 
the reacting phases may occur across the welded interfaces when several ingredients are milled together. Recently, many researches have applied MC technology to metal recovery from e-waste, such as waste fluorescent lamps (Tan et al., 2015), liquid-crystal display panels (Hasegawa et al., 2013), waste printed circuit boards (Ou and Li, 2014), cathode ray tube funnel glass (Yuan et al., 2012; Yuan et al., 2013), phosphors (Mio et al., 2001), spent lithium-ion batteries (Wang et al., 2016), and gold-containing waste (Ficeriová and Baláž, 2010) etc. The foregoing processes are mainly MC leaching, MC sulfidization, and mechanical activation. MC leaching produces aqueous slurry or solution of activated materials and requires milling pots and balls made of special materials (Tan and Li, 2015). MC sulfidization converts non-ferrous metals oxides into metal sulfides, followed by pyrometallurgy, a necessary posttreatment process (Guo et al., 2010). Mechanical activation involves an increase in the reactivity of target substances, which could promote the subsequent leaching process (Nasser and Mingelgrin, 2012). These techniques indicated that MC technology exhibited potential benefits for base metal recovery from e-waste. However, little attention has been paid to the recovery of precious metals. The influence of MC technology on precious metal recovery from e-waste with multiple metals is unknown.

In this study, a new ball milling method was attempted for $\mathrm{Cu}$ and precious metal recovery from e-waste. The specialty of this study was aimed to produce soluble metallic compound after treatment with dry ball milling and consequently benefit the subsequent leaching process. The mechanism of the ball milling process used in our study is different from the existing MC leaching process. MC induced solid-state reaction is essential for the ball milling process. New co-milling reagents need to be selected and optimized. In this study, we used dry MC process to recover valuable metals from e-waste scraps by co-milling with different reagents. After milling, metal recovery with dilute $\mathrm{HCl}$ was studied. Separation of Pd from the leaching solution and selective recovery of $\mathrm{Ag}$ from the indissoluble solid residue were investigated. The characteristics of samples after milling were studied and the mechanism of MC induced solid-state reaction was proposed.

\section{Materials and methods}

\subsection{Materials}

E-waste scraps used in this work were supplied by XIAMEN OASIS Sources CO. Ltd., which were mainly composed of multilayer ceramic capacitors (MLCCs) and waste PCBsPCBs. Almost all of the components (relays, capacitors, etc.) were disassembled from the PCBs when we received these materials. The bare PCBs were pretreated with a thermal shock process and crushed in a hammer crusher. Then, a centrifugal air separator was used to obtain the metallic components (Zhang and Zhang, 2013). MLCCs, which contains high content of $\mathrm{Ag}$ and Pd, were used as the raw materials along with the metallic components from bare PCBs. The metallic components and MLCCs were mixed and sent to comminute in a cutting mill until the fraction reached particle size smaller than $0.25 \mathrm{~mm}$ (referred to as "e-waste particles"). Metal contents in the obtained e-waste particles were measured by inductively coupled plasma-optical emission spectrometer (ICPOES, Prodigy, Leeman, USA) after $\mathrm{HNO}_{3}-\mathrm{HF}-\mathrm{HClO}_{4}$ digestion, as described in details in our precious study (Zhang and Zhang, 2013). The contents of major metallic elements are given in Table 1. As shown in Table.1, the highest content of element was $\mathrm{Cu}$ (57.11\%), and followed by $\mathrm{Zn}(15.55 \%) . \mathrm{Zn}$ in the e-waste scraps has an uncommon high content, which is found to be from MLCCs (see Fig. S1). Pd and Ag were the main precious metals while Au was not detected in the e-waste scraps used in this study because
Table 1

Metal contents in the e-waste scraps used for ball milling experiments (wt.\%).

\begin{tabular}{llll}
\hline Elements & Content (wt.\%) & Elements & Content (wt.\%) \\
\hline $\mathrm{Ag}$ & 2.74 & $\mathrm{Ni}$ & 1.11 \\
$\mathrm{Pd}$ & 0.28 & $\mathrm{Co}$ & 0.21 \\
$\mathrm{Cu}$ & 57.11 & $\mathrm{~Pb}$ & 0.25 \\
$\mathrm{Zn}$ & 15.55 & $\mathrm{Fe}$ & 0.20 \\
$\mathrm{Bi}$ & 2.27 & $\mathrm{Al}$ & 0.10 \\
$\mathrm{Sb}$ & 0.47 & & \\
\hline
\end{tabular}

of the dismantlement of electronic components. All of the chemical reagents used in the experiments were purchased from Chemical Reagent Company of Beijing in analytical grade.

\subsection{Ball milling and leaching experiments}

A planetary ball mill (QM-3SP2, Nanjing University Instrument Corporation, China) was used in the experiments. During the ball milling process, co-milling reagents and e-waste particles were put together into a $250 \mathrm{~mL}$-capacity corundum pot $(100 \mathrm{~mm}$ in diameter) with $120 \mathrm{~g}$ zirconia balls ( $9 \mathrm{~mm}$ in diameter). After milling for the predetermined time, the samples were collected and preserved for further use. Totally six group of co-milling reagents were used to mill with e-waste particles for the selection of an appropriate co-milling system. They are $\mathrm{NaCl}, \mathrm{NH}_{4} \mathrm{Cl}$, EDTA.2Na and the mixture of $\mathrm{K}_{2} \mathrm{~S}_{2} \mathrm{O}_{8}$ (a strong solid oxidant) and each of the above three reagents. Various ball milling parameters, including mass ratio of $\mathrm{K}_{2} \mathrm{~S}_{2} \mathrm{O}_{8}$ to $\mathrm{NaCl}$, mass ratio of co-milling reagents to e-waste particles, rotation speed and milling time, were also test during the experiment.

After milling, the ground sample was mixed in $0.5 \mathrm{~mol} / \mathrm{L}$ diluted hydrochloric acid $(\mathrm{HCl})$ (phase ratios, $\mathrm{V} / \mathrm{w}=40$ ) and the mixture was stirred by a magnetic stirrer in a flask for $15 \mathrm{~min}$ at room temperature. Then, the mixture was filtrated by a suction filter $(0.22 \mu \mathrm{m})$ and the residue was collected and dried in an oven at $105^{\circ} \mathrm{C}$. The filtrate was measured by ICP-OES to determine the recovery efficiency of $\mathrm{Cu}, \mathrm{Ag}$, $\mathrm{Pd}$ and $\mathrm{Zn}$. Pd in the leaching solution was recovered by diisoamyl sulfides olvent extraction, same with our previous study (Zhang and Zhang, 2014). Ag in the residue was then leached with $1 \mathrm{~mol} / \mathrm{L} \mathrm{NH}_{3}$ solution for $15 \mathrm{~min}$ and reduced by hydrazine hydrate to precipitate $\mathrm{Ag}$. The above process was shown in Fig. 1.

\subsection{Characterization of the materials}

The chemical composition changes and morphology information of the solid samples during the ball milling process were characterized. The crystalline phases of the samples before and after ball milling were characterized by X-ray diffraction spectroscopy (XRD, Rigaku D/max 2500) using $\mathrm{Cu} \mathrm{K \alpha}$ radiation $(\gamma=1.5418 \AA$ ) with $30 \mathrm{kV}$ voltage and $30 \mathrm{~mA}$ current. X-ray photoelectron spectroscopy (XPS) measurement was carried out with an ESCALAB $250 \mathrm{Xi}$ spectrometer (Thermo Scientific) with $\mathrm{Al} \mathrm{K \alpha}$ radiation $(\mathrm{h} v=1253.6 \mathrm{eV})$. Morphology of the samples before and after mechanochemical treatment was observed on a JSM-7001F field emission scanning electron microscopy (FESEM). Size distribution of the e-waste scraps before milling is measured with a Laser Particle Size Analyzers (Mastersize 2000, Malvern, UK)

\section{Results and discussion}

\subsection{Comparison of different Co-milling reagents}

It is known that $\mathrm{Cu}$ could not be leached with dilute $\mathrm{HCl}$ under room temperature without oxidant. As can be seen from 


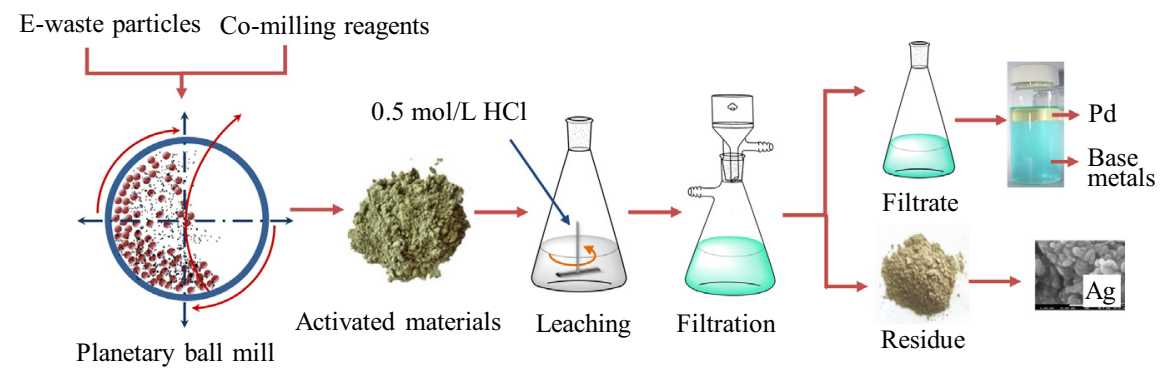

Fig. 1. Flowchart of the ball milling and leaching process.
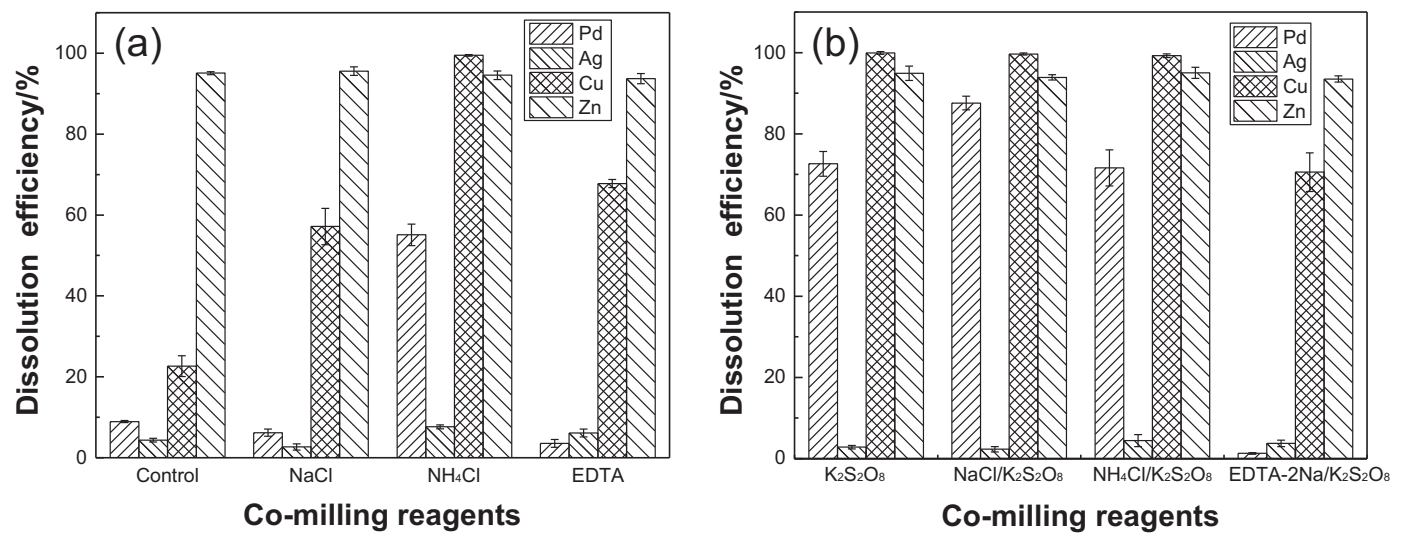

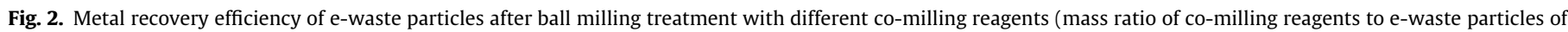
$3: 1$, rotation speed of $600 \mathrm{rpm}$, milling time of $6 \mathrm{~h}$; Without co-milling agent in the control experiments).

Fig. 2a, 22.6\% of $\mathrm{Cu}$ was leached with dilute $\mathrm{HCl}$ after ball milling without co-milling reagent, implying that ball milling could change the leaching behavior of $\mathrm{Cu}$ and promote the leaching process. After the addition of co-milling reagents, recovery efficiency of Cu was significantly increased. Recovery efficiency of Pd was only promoted by co-milling with $\mathrm{NH}_{4} \mathrm{Cl}$. The recovery efficiency with $\mathrm{NH}_{4} \mathrm{Cl}$ was nearly $100 \%$ for $\mathrm{Cu}$ and $57.2 \%$ for Pd. In this case, $\mathrm{K}_{2} \mathrm{~S}_{2} \mathrm{O}_{8}$, an oxidant often used in advanced oxidation technologies (Huang et al., 2016), was added to the ball milling to further increase metal recovery efficiency. By comparing Fig. 2a with b, it can be seen that recovery efficiency of Pd was significantly enhanced for $\mathrm{NaCl}$ and $\mathrm{NH}_{4} \mathrm{Cl}$ after the addition of $\mathrm{K}_{2} \mathrm{~S}_{2} \mathrm{O}_{8}$, especially $\mathrm{NaCl}$. After the addition of $\mathrm{K}_{2} \mathrm{~S}_{2} \mathrm{O}_{8}$, the recovery efficiency of $\mathrm{Pd}$ for $\mathrm{NaCl}$ and $\mathrm{NH}_{4} \mathrm{Cl}$ increased, respectively, from $6.2 \%$ to $87.5 \%$ and from $55.1 \%$ to $71.6 \%$. As can be seen from Fig. $2 \mathrm{~b}$, the order of the recovery efficiency of Pd was as follows: $\mathrm{K}_{2} \mathrm{~S}_{2} \mathrm{O}_{8}$ / $\mathrm{NaCl}>\mathrm{K}_{2} \mathrm{~S}_{2} \mathrm{O}_{8}>\mathrm{K}_{2} \mathrm{~S}_{2} \mathrm{O}_{8} / \mathrm{NH}_{4} \mathrm{Cl}>\mathrm{K}_{2} \mathrm{~S}_{2} \mathrm{O}_{8} /$ EDTA.2Na. After MC treatment with $\mathrm{K}_{2} \mathrm{~S}_{2} \mathrm{O}_{8} / \mathrm{NaCl}$, recovery efficiency of Pd achieved $87.5 \%$.

It is interesting to note that the mixture of the $\mathrm{NaCl}$ and $\mathrm{K}_{2} \mathrm{~S}_{2} \mathrm{O}_{8}$ was superior to single addition of $\mathrm{NaCl}$ or $\mathrm{K}_{2} \mathrm{~S}_{2} \mathrm{O}_{8}$ for the ball milling process. The recovery efficiency of Pd after milled with $\mathrm{NaCl} / \mathrm{K}_{2} \mathrm{~S}_{2} \mathrm{O}_{8}$ was $15 \%$ higher than that with $\mathrm{K}_{2} \mathrm{~S}_{2} \mathrm{O}_{8}, 82.3 \%$ higher than that with $\mathrm{NaCl}$, respectively. This suggests that $\mathrm{NaCl}$ and $\mathrm{K}_{2} \mathrm{~S}_{2} \mathrm{O}_{8}$ may play different roles during the ball milling process. In reviewing the literature, it is considered that leaching of metals, especially precious metals, depends on ligands and oxidants in metallurgical process (Jianmin, 2010; Senanayake, 2012). Accordingly, we can infer that during the ball milling process, the MC reactions of metals are influenced by both ligands and oxidants. Researches showed that $\mathrm{K}_{2} \mathrm{~S}_{2} \mathrm{O}_{8}$ was transformed into sulfate under the activation of ball milling. The activation of persulfate supported an oxidation process (Huang et al., 2016; Liu et al., 2016). This suggests that $\mathrm{K}_{2} \mathrm{~S}_{2} \mathrm{O}_{8}$ played the role of oxidant during the ball milling process. Pd is known to form unstable metal complexes with sulfate while the chelates of Pd with halogen are much more stable (Hartley, 2013; Kragten, 1980). So, it may be the case that Pd was oxidized by $\mathrm{K}_{2} \mathrm{~S}_{2} \mathrm{O}_{8}$ and formed chelates with chlorine during the ball milling process. Hence, $\mathrm{NaCl}$ and $\mathrm{K}_{2} \mathrm{~S}_{2} \mathrm{O}_{8}$ played the role of ligand and oxidant, respectively, during the ball milling process.

It can also be seen from Fig. 2 that the ball milling process had little effect on the recovery of Zn. Recovery efficiency of Zn was about $95 \%$ under any co-milling reagent. The results are likely to be related to the different chemical states of $\mathrm{Zn}$ in the e-waste particles. $\mathrm{Zn}$ element in the e-waste particles is mainly from MLCC, and it is in oxidation state (Zincite, ZnO, Fig. S1) and can be dissolved in $\mathrm{HCl}$ without any pretreatment. Since the ball milling process had little effect on the recovery of $\mathrm{Zn}$, data of $\mathrm{Zn}$ was not shown in the subsequent figures.

According to the above analysis, after MC treatment, there's no significant difference in different co-milling reagents with the recovery of $\mathrm{Zn}$ and $\mathrm{Ag}$. Recovery efficiency of $\mathrm{Cu}$ and $\mathrm{Pd}$ achieved the highest level of $99.6 \%$ and $87.5 \%$, respectively, under $\mathrm{K}_{2} \mathrm{~S}_{2} \mathrm{O}_{8} /$ $\mathrm{NaCl}$. Therefore, $\mathrm{K}_{2} \mathrm{~S}_{2} \mathrm{O}_{8} / \mathrm{NaCl}$ was chosen as the co-milling reagents in the subsequent experiments.

\subsection{Possible mechanism of MC reactions}

To better understand the mechanism during ball milling process, characterization of the e-waste scraps before and after ball milling was studied. As shown in Fig. 3, X-ray Diffraction (XRD) was used to clarify the phase change of samples before and after milling. Several significant changes were observed. It is found that the peaks in the XRD patterns decreased in intensity and broadened after ball milling, suggesting dramatic size reduction and crystal dislocation or defects during ball milling (Motozuka et al., 2014). The peaks associated with $\mathrm{K}_{2} \mathrm{~S}_{2} \mathrm{O}_{8}$ disappeared and the 


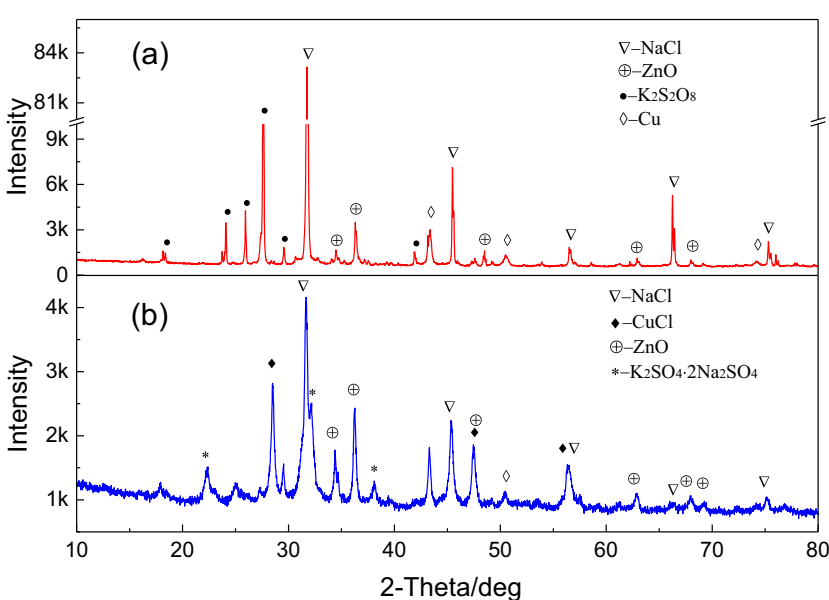

Fig. 3. XRD pattern of the sample before (a) and after (b) ball milling.

peaks corresponding to $\mathrm{K}_{2} \mathrm{SO}_{4}$ were detected, indicating that most $\mathrm{K}_{2} \mathrm{~S}_{2} \mathrm{O}_{8}$ was transformed into $\mathrm{K}_{2} \mathrm{SO}_{4}$ or amorphous $\mathrm{K}_{2} \mathrm{~S}_{2} \mathrm{O}_{8}$. It was also observed from the XRD patterns that the peaks of $\mathrm{Cu}$ disappeared and the peaks corresponding to cuprous chloride $(\mathrm{CuCl})$ were detected after ball milling. This result indicated that metallic $\mathrm{Cu}$ was oxidized and transformed into $\mathrm{CuCl}$ during ball milling. It is worth noting that the milled sample was changed from dark brown to light green. As it is known that $\mathrm{CuCl}$ is white crystalline powder and cupric $(\mathrm{Cu}(\mathrm{II}))$ salt is green. This phenomenon indicates that cupric ( $\mathrm{Cu}(\mathrm{II}))$ salts may be generated during ball milling. Therefore, it is suggested that metallic $\mathrm{Cu}$ in the sample was oxidized into different valence states after ball milling.
To confirm the speculation, the chemical composition of the milled sample was further investigated by XPS spectra. The widescan XPS spectrum and deconvoluted XPS spectra are presented in Fig. 4a and b-d, respectively. From the Cu 2p spectrum (Fig. 4b), it can be found that the peaks at $952.2 \mathrm{eV}$ and $932.4 \mathrm{eV}$ were attributable to $\mathrm{Cu}(\mathrm{I})$, while the peaks at $934.2 \mathrm{eV}$ and 954.3 were attributable to $\mathrm{Cu}(\mathrm{II})$ (Fu et al., 2012; Zhao and Peng, 2012). The $\mathrm{Cu}(\mathrm{II})$ related shake-up satellite in the binding energy of $943 \mathrm{eV}$ was also clearly observed in the spectra, which further confirmed the presence of Cu(II) (Chawla et al., 1992; Mekki et al., 1997). The result supported the above inference of XRD that both of $\mathrm{Cu}(\mathrm{I})$ and $\mathrm{Cu}$ (II) were presented in the milled sample. It was calculated that the normalized $\mathrm{Cu}(\mathrm{I})$ peak area was 3 times size of that of $\mathrm{Cu}(\mathrm{II})$, suggesting that approximately $75 \%$ of the $\mathrm{Cu}$ in the initial sample was oxidized into $\mathrm{Cu}(\mathrm{I})$ and $25 \%$ of the $\mathrm{Cu}$ was oxidized into $\mathrm{Cu}$ (II). The XPS Ag $3 \mathrm{~d}$ spectrum of the milled sample shown in Fig. $4 \mathrm{c}$ is helpful to study the behavior of $\mathrm{Ag}$ in the sample during milling. The peak of $368.2 \mathrm{eV}$ and $374.3 \mathrm{eV}$ was attributed to $\mathrm{Ag}(\mathrm{I})$ (Liu et al., 2008), indicating the oxidation of $\mathrm{Ag}$ to $\mathrm{Ag}(\mathrm{I})$ during the ball milling process. Although $\mathrm{Ag}$ was oxidized into $\mathrm{Ag}(\mathrm{I})$, there was still only about $5 \%$ of $\mathrm{Ag}$ dissolved during the leaching process. Therefore, considering the high content of $\mathrm{Cl}$ in the milled sample, this result may be explained by the fact that $\mathrm{Ag}$ was precipitated as $\mathrm{AgCl}$ during the ball milling and leaching process. Fig. 4d shows the $\mathrm{S} 2 \mathrm{p}$ spectrum of the milled sample. The most prominent peaks located at $168.9 \mathrm{eV}$ and $170.0 \mathrm{eV}$ were attributed to $\mathrm{SO}_{4}^{2-}$. Studies on $\mathrm{SO}_{4}^{2-}$ indicated that a small shift may occur in binding energy of the $\mathrm{S} 2 \mathrm{p}$ peaks depending on metal cations. The peak at $170.0 \mathrm{eV}$ may be attributed to $\mathrm{CuSO}_{4}$ (Chawla et al., 1992; Kurmaev et al., 1996), which was shifted toward higher energy by $1.1 \mathrm{eV}$ compared with the peak at $168.9 \mathrm{eV}$ for $\mathrm{K}_{2} \mathrm{SO}_{4}$ or $\mathrm{Na}_{2} \mathrm{SO}_{4}$ (Lindberg et al., 1970; Yu et al., 1990). The results of XRD and XPS confirmed that $\mathrm{S}_{2} \mathrm{O}_{8}^{2-}$ transformed into $\mathrm{SO}_{4}^{2-}$ during ball milling.
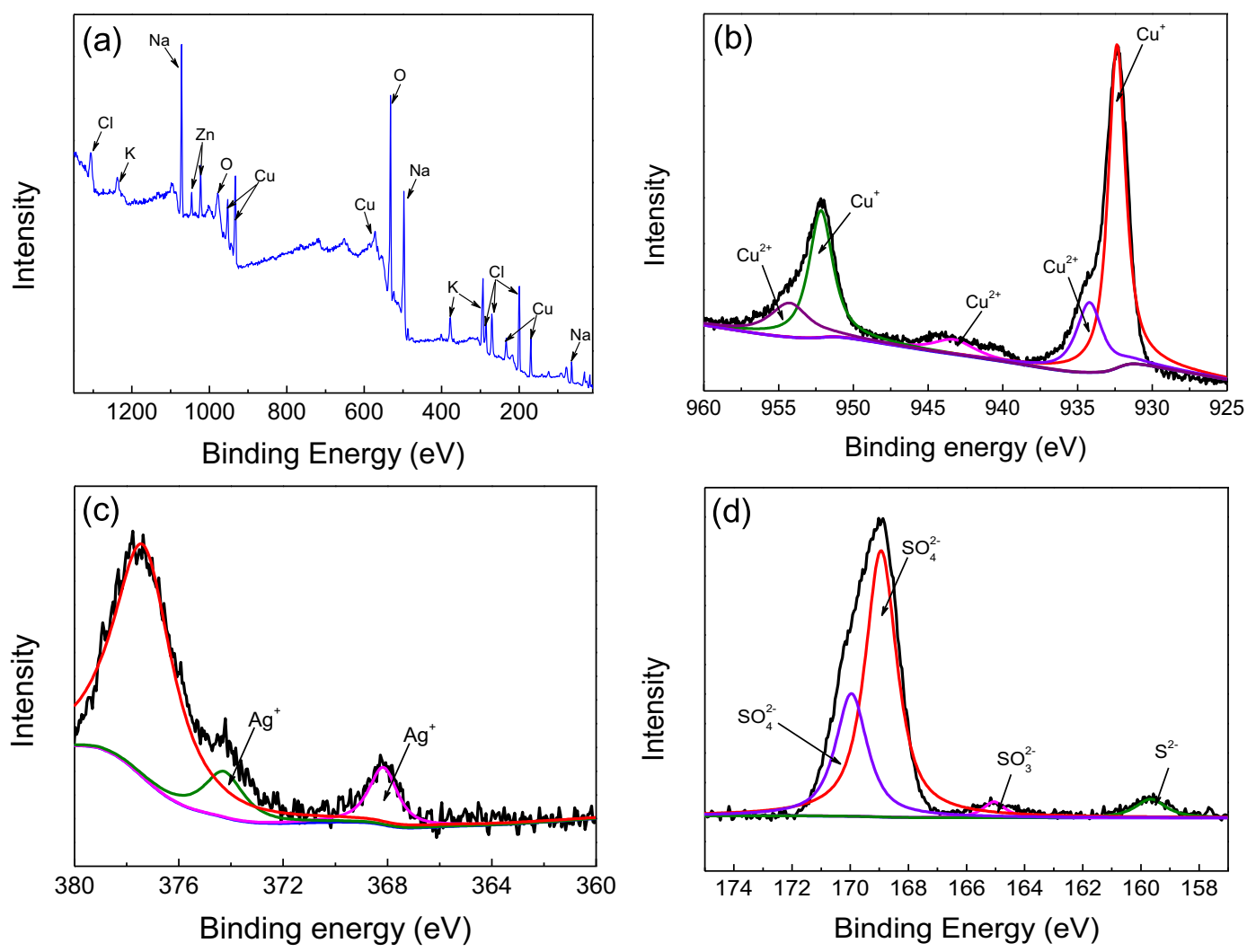

Fig. 4. The wide-scan XPS spectrum (a) and deconvoluted XPS spectra (b-d) of the milled sample. 

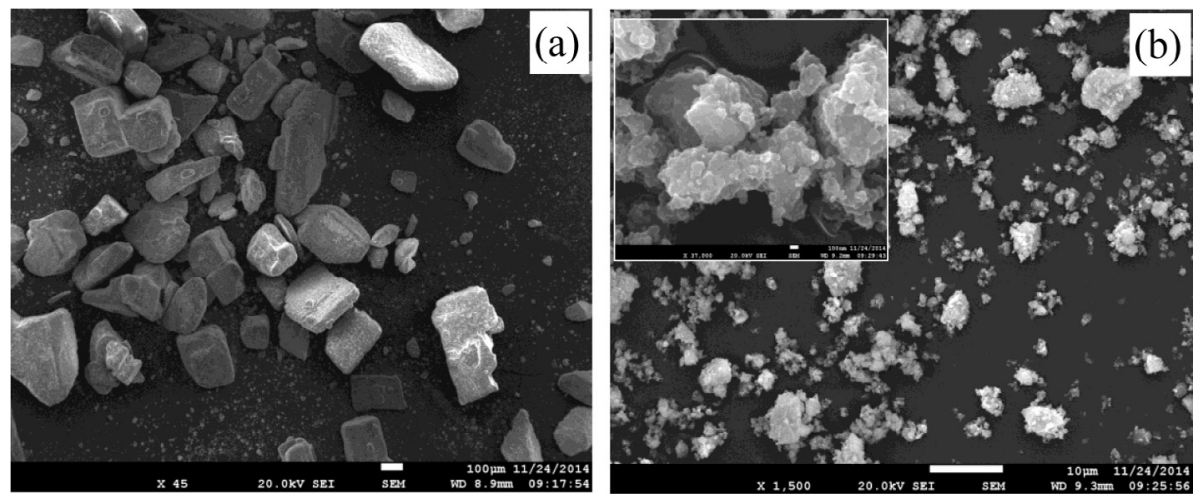

Fig. 5. SEM image of the sample before (a) and after (b) ball milling.

Fig. 5 shows the morphology changes of the sample before and after ball milling. It can be seen that the samples after ball milling have much smaller particles and loose surface morphology, compared to samples before ball milling. The initial sample consisted of angular and compact particles (Fig. 5a). After milling for $3 \mathrm{~h}$, pulverization, amorphization and grain refinement occurred and loosely packed agglomeration formed under the mechanical force (Fig. 5b). The inset higher magnification image shows that the agglomerated particles were piled up with thin layers. Size distribution of the e-waste scraps before and after milling is measured with a Laser Particle Size Analyzers. The average particle size is $49.28 \mu \mathrm{m}$ and $\mathrm{d}(50)$ is $3.88 \mu \mathrm{m}$ before ball milling. After milling, the average particle size was significantly decreased. The average particle size decreased to $2.40 \mu \mathrm{m}$ and $\mathrm{d}(50)$ decreased to $0.23 \mu \mathrm{m}$. The result of SEM image and particle size analysis further improved the above inference from XRD that dramatic size reduction and crystal dislocation or defects occurred during ball milling.

To further understand the MC reactions occurred during ball milling process, the probable MC reactions are listed in Table 2 and the corresponding thermodynamic parameters were calculated. Thermodynamic calculations in Table 2 indicate that $\Delta \mathrm{G}_{298}$ of all the reactions are negative, which shows that all the reactions are favorable in theory. However, According to the data in reference, the negative $\Delta G$ of reactions is found to be necessary but not sufficient for the occurrence of the reaction (Chai et al., 2013; Takacs, 2002). It can be observed that $\Delta G$ of the reactions are significantly lower with the participation of $\mathrm{NaCl} . \Delta \mathrm{G}$ of reaction 1 is the lowest among all of the 10 probable reactions, meaning that reaction 1 is most likely to occur during milling. XPS result showed that part of $\mathrm{Cu}$ in the sample was oxidized into $\mathrm{Cu}(\mathrm{II})$, suggesting the occurrence of reaction 2. Among the 3 reactions related to $\mathrm{Ag}, \Delta \mathrm{G}$ of reaction 6 is much lower than reaction 7 and 8 , implying that reaction 6 is the most probable reaction. Referring back to the XPS analysis that $\mathrm{Ag}$ was oxidized to $\mathrm{Ag}(\mathrm{I})$, it could be assumed that
$\mathrm{AgCl}$ was generated during the ball milling process. For Pd, $\Delta \mathrm{G}$ of reaction 9 is lower than reaction 10 . It is probably that the Pd related reaction was proceeded according to reaction 9 during the ball milling process.

Base on the above analysis, a possible reaction mechanism is proposed to explain the MC reactions. Under the activation of ball milling process, $\mathrm{K}_{2} \mathrm{~S}_{2} \mathrm{O}_{8}$ played the role of oxidant while the addition of $\mathrm{NaCl}$ reduced the activation energy of the reactions. Besides, ball milling could reduce the particle size and thoroughly mix the components, resulting in an increase of the active interface area between the reacting components. Meanwhile, lattice defects were created to provide chemically active sites and fast diffusion paths (Takacs, 2009; Tsuzuki et al., 1997). Researches showed that local transient temperatures induced by impact of the ball did not exceed $110^{\circ} \mathrm{C}$ in which mechanochemical energy allowed reactions between the metals and ligands. This suggests that local melting could not account for the reaction(Garay et al., 2007). The solid-solid reaction occurred in our experiment is also between metals and ligands. It is possible to hypothesize that local transient temperatures induced in the ball milling process was below $110^{\circ} \mathrm{C}$. As a consequence, solid-solid reactions, which would normally require high temperature to occur due to separation of the reacting phases, can occur at low temperature in ball milling. Soluble metallic compounds were produced after treatment with dry ball milling and consequently benefit the subsequent leaching process. According to the above discussion, possible reactions occurred during ball milling process is expressed as the following reaction:

$$
\begin{aligned}
& \mathrm{K}_{2} \mathrm{~S}_{2} \mathrm{O}_{8}+2 \mathrm{NaCl}+\mathrm{nM}^{\text {ball milling }} \rightarrow \mathrm{nMCl}_{2 / \mathrm{n}}+\mathrm{K}_{2} \mathrm{SO}_{4}+\mathrm{Na}_{2} \mathrm{SO}_{4} \\
& \text { If } \mathrm{M}=\mathrm{Cu}, n=1 \text { and } 2 \text { (two reactions for } \mathrm{Cu} \text { ). } \\
& \text { If } \mathrm{M}=\mathrm{Ag}, n=2 \text {. } \\
& \text { If } \mathrm{M}=\mathrm{Pd}, n=1 .
\end{aligned}
$$

Table 2

Probable MC reactions and the corresponding thermodynamic parameters during the ball milling process (298-383 K).

\begin{tabular}{llll}
\hline Elements & NO. & Reactions & $\Delta \mathrm{G}(298-383 \mathrm{~K}, \mathrm{~kJ} / \mathrm{mol})$ \\
\hline $\mathrm{Cu}$ & 1 & $\mathrm{~K}_{2} \mathrm{~S}_{2} \mathrm{O}_{8}+2 \mathrm{NaCl}+2 \mathrm{Cu}=2 \mathrm{CuCl}+\mathrm{K}_{2} \mathrm{SO}_{4}+\mathrm{Na}_{2} \mathrm{SO}_{4}$ & -364.9 to -365.95 \\
& 2 & $\mathrm{~K}_{2} \mathrm{~S}_{2} \mathrm{O}_{8}+2 \mathrm{NaCl}+\mathrm{Cu}=\mathrm{CuCl}_{2}+\mathrm{K}_{2} \mathrm{SO}_{4}+\mathrm{Na}_{2} \mathrm{SO}_{4}$ & -298.5 to -296.65 \\
& 3 & $\mathrm{~K}_{2} \mathrm{~S}_{2} \mathrm{O}_{8}+\mathrm{Cu}=\mathrm{K}_{2} \mathrm{SO}_{4}+\mathrm{CuSO}_{4}$ & -122.0 to -135.88 \\
& 4 & $\mathrm{~K}_{2} \mathrm{~S}_{2} \mathrm{O}_{8}+\mathrm{Cu}=\mathrm{K}_{2} \mathrm{SO}_{4}+\mathrm{SO}_{3}(\mathrm{~g})+\mathrm{CuO}$ & -141.8 to -157.01 \\
$\mathrm{Ag}$ & 5 & $\mathrm{~K}_{2} \mathrm{~S}_{2} \mathrm{O}_{8}+2 \mathrm{Cu}=\mathrm{K}_{2} \mathrm{SO}_{4}+\mathrm{SO}_{3}(\mathrm{~g})+\mathrm{Cu}_{2} \mathrm{O}$ & -344.4 to -345.28 \\
& 6 & $\mathrm{~K}_{2} \mathrm{~S}_{2} \mathrm{O}_{8}+2 \mathrm{NaCl}+2 \mathrm{Ag}=2 \mathrm{AgCl}_{2} \mathrm{~K}_{2} \mathrm{SO}_{4}+\mathrm{Na}_{2} \mathrm{SO}_{4}$ & -242.3 to -243.34 \\
$\mathrm{Pd}$ & 7 & $\mathrm{~K}_{2} \mathrm{~S}_{2} \mathrm{O}_{8}+2 \mathrm{Ag}=\mathrm{K}_{2} \mathrm{SO}_{4}+\mathrm{Ag}_{2} \mathrm{SO}_{4}$ & -5.132 to -21.16 \\
& 8 & $\mathrm{~K}_{2} \mathrm{~S}_{2} \mathrm{O}_{8}+2 \mathrm{Ag}=\mathrm{K}_{2} \mathrm{SO}_{4}+\mathrm{SO}_{3}(\mathrm{~g})+\mathrm{Ag}_{2} \mathrm{O}$ & -251.2 to -248.67 \\
& 9 & $\mathrm{~K}_{2} \mathrm{~S}_{2} \mathrm{O}_{8}+2 \mathrm{NaCl}+\mathrm{Pd}_{2} \mathrm{PdCl}_{2}+\mathrm{K}_{2} \mathrm{SO}_{4}+\mathrm{Na}_{2} \mathrm{SO}_{4}$ & -77.4 to -90.28 \\
\hline
\end{tabular}




\subsection{Optimization of ball milling parameters}

During the ball milling process, there are many factors affecting the $\mathrm{MC}$ reaction performance and metal recovery efficiency. Therefore, a series of experiments were further conducted to optimize the ball milling parameters and the results are shown in Fig. 6 . As shown in Fig. 6a, the mass ratio of $\mathrm{K}_{2} \mathrm{~S}_{2} \mathrm{O}_{8}$ to $\mathrm{NaCl}$ had a significant impact on $\mathrm{Pd}$ recovery efficiency while $\mathrm{Cu}$ (over 99\%) and $\mathrm{Ag}$ (around 5\%) were not affected. Pd recovery efficiency increased rapidly from $32.7 \%$ to $87.6 \%$ when the mass ratio of $\mathrm{K}_{2} \mathrm{~S}_{2} \mathrm{O}_{8}$ to $\mathrm{NaCl}$ increased from $1: 3$ to $1: 1$. But with the further increase of the ratio, recovery efficiency of $\mathrm{Pd}$ showed no significant change, implying that the amount of $\mathrm{K}_{2} \mathrm{~S}_{2} \mathrm{O}_{8}$ was sufficient for the ball milling system with the mass ratio of $1: 1$. On the basis of the above results, the optimal $\mathrm{K}_{2} \mathrm{~S}_{2} \mathrm{O}_{8}$ to $\mathrm{NaCl}$ mass ratio was determined to be $1: 1$ and the subsequent experiments were conducted with this condition.

Fig.6b shows the effect of the mass ratio of co-milling reagents to e-waste particles on metal recovery. The results indicated that higher mass ratios resulted in relatively better performance in terms of metal recovery. The recovery efficiency of Pd increased steadily as the mass ratio increased from $1: 1$ to $4: 1$ and then stayed unchanged. $\mathrm{Cu}$ can be completely dissolved when the mass ratio was higher than 2:1 while $\mathrm{Ag}$ recovery efficiency was not affected by the mass ratio. Although high recovery efficiency can be achieved with high mass ratio, more co-milling reagent was needed as the mass ratio increases. Therefore, $4: 1$ was the optimal mass ratio as both $\mathrm{Cu}$ and $\mathrm{Pd}$ could obtain high recovery efficiency under this condition.

According to Heegn (1986), the specific milling energy $E_{\mathrm{M}}$ can be defined by Eq. (2):
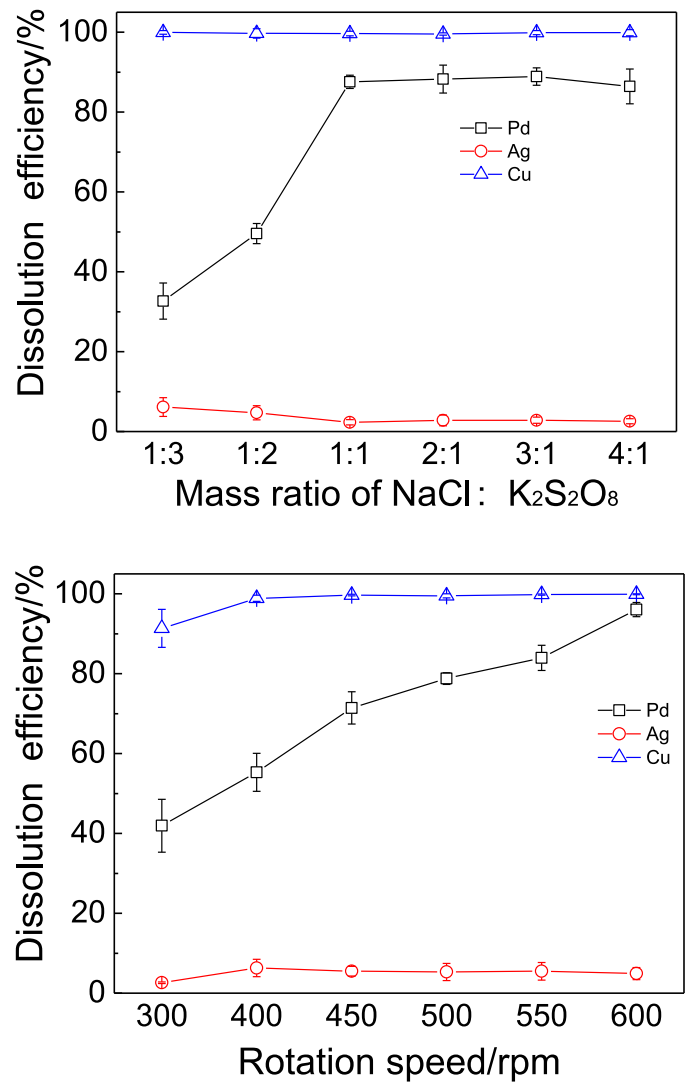

$E_{M}=\frac{m_{B}}{m_{S}} \mathrm{bnt}_{M} D$

where $m_{\mathrm{B}}, m_{\mathrm{S}}, t_{\mathrm{M}}, n, b$ and $D$ refer to the weight of balls, the weight of sample, milling time, rotation speed, acceleration in planetary mill, and mill diameter, respectively. It can be deduced from Eq. (2) that the specific milling energy is in proportion to the rotation speed of the mill rotation speed, implying that rotation speed is an important factor affecting the performance of $\mathrm{MC}$ reactions. Therefore, the effect of rotation speed was studied. As can be seen from Fig. 6c, the recovery efficiency of Pd increased from $41.9 \%$ to $96.1 \%$ as the rotation speed increased from $300 \mathrm{rpm}$ to $600 \mathrm{rpm}$. The recovery efficiency of $\mathrm{Cu}$ increased slightly with the rotation speed increasing from 300 to 400 and then stayed unchanged. The above results suggested that $600 \mathrm{rpm}$ was the appropriate rotation speed for the MC reaction.

Fig. $6 \mathrm{~d}$ shows the effect of milling time on metal recovery. As can be seen from the figure, $\mathrm{Cu}$ was completely dissolved after only 15 min milling, implying a fast MC reaction during ball milling. Recovery efficiency of Pd increased rapidly in the beginning and then stabilized around $96 \%$ in the later stage of the experiment. The recovery efficiency of $\mathrm{Ag}$ remained around 5\% with all of the milling conditions. On the basis of the above results, the optimal time for ball milling was $3 \mathrm{~h}$. Under this condition, the recovery efficiency of $\mathrm{Cu}$ and $\mathrm{Pd}$ were $99.9 \%$ and $95.5 \%$, respectively while only $5.3 \%$ of $\mathrm{Ag}$ was dissolved.

\subsection{Selective recovery of precious metals after ball milling process}

Pd recovery from the leaching solution was carried out by solvent extraction according to our previous study (Zhang and
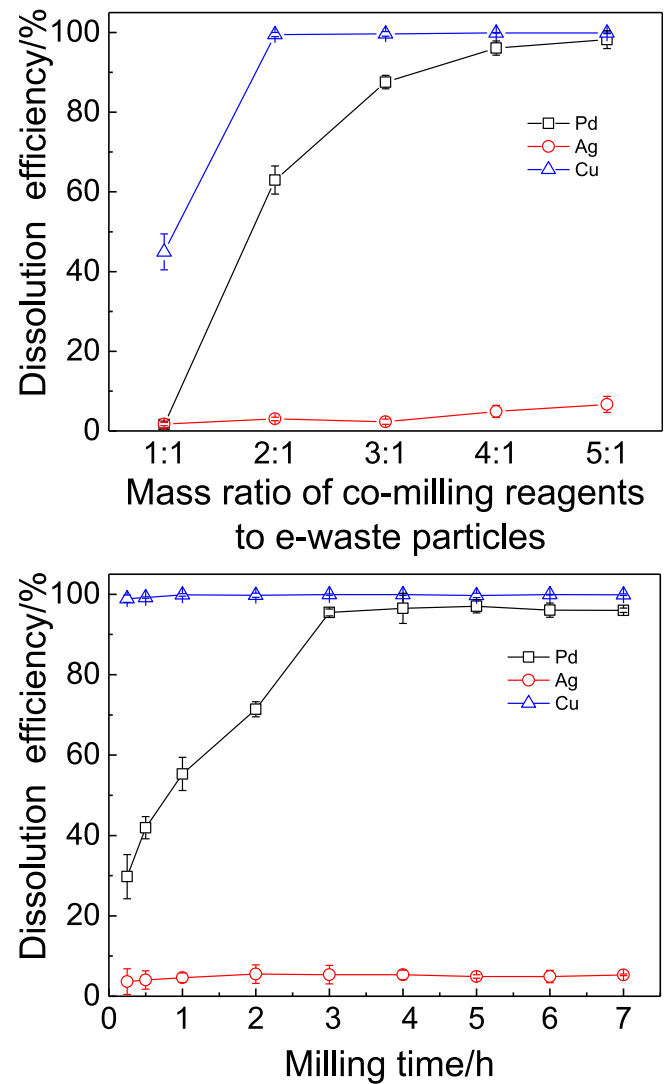

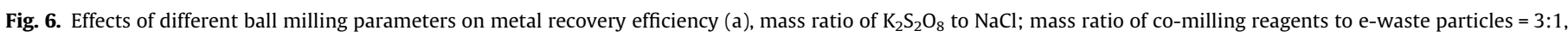

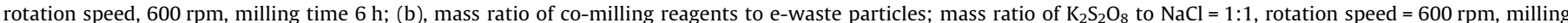

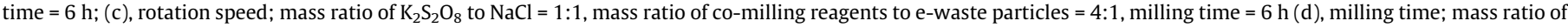
$\mathrm{K}_{2} \mathrm{~S}_{2} \mathrm{O}_{8}$ to $\mathrm{NaCl}=1: 1$, mass ratio of co-milling reagents to e-waste particles $=4: 1$; rotation speed $=600 \mathrm{rpm}$. 
Table 3

Extraction efficiency, distribution ratio and separation coefficient during the Pd extraction process.

\begin{tabular}{|c|c|c|c|c|c|c|c|c|}
\hline Elements & Pd & $\mathrm{Ag}$ & $\mathrm{Cu}$ & $\mathrm{Pb}$ & $\mathrm{Zn}$ & $\mathrm{Ni}$ & $\mathrm{Sb}$ & $\mathrm{Bi}$ \\
\hline $\mathrm{E}(\%)$ & 98.57 & 23.63 & 0.15 & 1.42 & 0.19 & 0.08 & 0.19 & 0.01 \\
\hline $\mathrm{D}_{\mathrm{M}}$ & 70.35 & 0.25 & 0.00 & 0.01 & 0.00 & 0.00 & 0.00 & 0.00 \\
\hline$S_{M}^{\mathrm{Pd}}$ & - & $2.83 \times 10^{2}$ & $4.78 \times 10^{4}$ & $4.89 \times 10^{3}$ & $3.67 \times 10^{4}$ & $8.65 \times 10^{4}$ & $3.64 \times 10^{4}$ & $5.29 \times 10^{4}$ \\
\hline
\end{tabular}

1. $\mathrm{D}_{\mathrm{M}}$ : distribution ratio, $S_{M}^{\mathrm{Pd}}$ : separation coefficient. 2 . The calculation method of $\mathrm{E}, \mathrm{D}_{\mathrm{M}}$ and $S_{M}^{\mathrm{Pd}}$ is shown in the supplementary materials.

Table 4

Metal contents of the leaching residue (XRF, wt.\%).

\begin{tabular}{llll}
\hline Elements & Content/\% & Elements & Content/\% \\
\hline $\mathrm{Ag}$ & 19.77 & $\mathrm{Cu}$ & 0.04 \\
$\mathrm{Al}$ & 29.87 & $\mathrm{Zn}$ & 3.04 \\
$\mathrm{Zr}$ & 3.84 & $\mathrm{Sb}$ & 1.05 \\
$\mathrm{Bi}$ & 3.00 & $\mathrm{Fe}$ & 0.27 \\
$\mathrm{Sn}$ & 0.27 & $\mathrm{Ni}$ & 0.19 \\
$\mathrm{Co}$ & 0.14 & $\mathrm{~Pb}$ & 0.06 \\
\hline
\end{tabular}

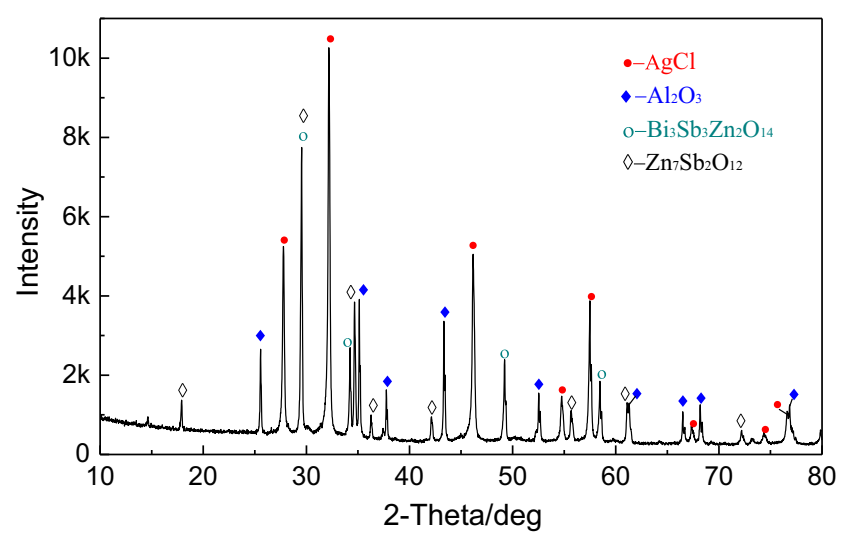

Fig. 7. XRD patterns of the leaching residue.

Zhang, 2014). Result in Table 3 indicated that more than 98\% of Pd (II) was extracted by diisoamyl sulfide while the extraction of base metals was negligible. Distribution ratio of Pd was 70.35 and separation coefficient of $\mathrm{Pd}(\mathrm{II})$ with base metals(M) was above 4000 .

XRF data (Table 4) and XRD pattern (Fig. 7) of the leaching residue indicated that the major components of the residue were $\mathrm{Al}_{2} \mathrm{O}_{3}, \mathrm{AgCl}, \mathrm{Bi}_{3} \mathrm{Sb}_{3} \mathrm{Zn}_{2} \mathrm{O}_{14}$ and $\mathrm{Zn}_{7} \mathrm{Sb}_{2} \mathrm{O}_{12}$. The content of $\mathrm{Ag}$ in the residue was $19.8 \%$, corresponding to $26.3 \%$ for $\mathrm{AgCl}$. $\mathrm{Ag}$ in the residue was leached with $1 \mathrm{~mol} / \mathrm{L} \mathrm{NH}_{4} \mathrm{OH}$ in $15 \mathrm{~min}$ according to the following reaction.

$$
\mathrm{AgCl}+2 \mathrm{NH}_{4} \cdot \mathrm{OH}=\mathrm{Ag}\left(\mathrm{NH}_{3}\right)_{2} \mathrm{Cl}+\mathrm{H}_{2} \mathrm{O}
$$

Results indicate that the metals in the residue were almost insoluble except $\mathrm{Ag}$ during the leaching process (Table S1). The solution was then reduced by sodium borohydride to precipitate Ag. Thus, Ag and Pd were successfully separated from base metals.

\subsection{Suggestion for e-waste collection for ball milling process}

According to the above discussion, $\mathrm{Cu}$, $\mathrm{Pd}$ and $\mathrm{Ag}$ could be successfully recovered from the e-waste scraps and $\mathrm{Pd}, \mathrm{Ag}$ were separated from base metals during the process. However, this study has raised important questions about e-waste recovery with ball milling process. It can be seen from Fig. 6 that recovery of $\mathrm{Cu}$ with ball milling process consumed much less co-milling reagents and time than Pd. Besides, lower ball milling speed was needed. Only 15 min was needed for $\mathrm{Cu}$ recovery under the optimum condition.
Table 5

Main components of PCBs and the category suggestion for ball milling process.

\begin{tabular}{lll}
\hline Categories & Components & $\begin{array}{l}\text { Metal } \\
\text { elements }\end{array}$ \\
\hline $\begin{array}{c}\text { Precious metal containing } \\
\text { category }\end{array}$ & $\begin{array}{l}\mathrm{IC} \\
\text { Contacts } \\
\text { MLCCs } \\
\text { Thin film chip resistors }\end{array}$ & $\begin{array}{l}\mathrm{Cu}, \mathrm{Au} \\
\mathrm{Cu}, \mathrm{Au} \\
\mathrm{Ag}, \mathrm{Au}, \mathrm{Pd}\end{array}$ \\
& Bare Mobile phone PCBs & $\mathrm{Cu}, \mathrm{Ag}, \mathrm{Au}$ \\
Cu rich category & Bare TV PCBs & $\mathrm{Cu}, \mathrm{Sn}, \mathrm{Pb}$ \\
& Bare PC PCBs & $\mathrm{Cu}, \mathrm{Sn}$ \\
Frames category & Relays & $\mathrm{Cu}$ \\
& USB frame, CPU frame, Line & $\mathrm{Fe}, \mathrm{Al}$ \\
Battery category & interface frame & $\mathrm{Li}, \mathrm{Mn}$ \\
\hline
\end{tabular}

It is reasonable to treat these metals separately. It is known that the composition of e-waste can change significantly in the wake of technical, economic and social developments (Morf et al., 2007). Valuable metals in different electrical and electronic equipments or different components of e-waste may differ greatly (Charles et al., 2017). Thus, it is suggested that electrical and electronic equipments should collect separately during gathering process. Before treatment with ball milling process, different components of e-waste should be classified.

According to our measurement, precious metals are mainly exists in the electron components, such as IC, Contacts, MLCCs and thin film chip resistors. The bare mobile phone PCBs also contains high content of $\mathrm{Ag}$ and $\mathrm{Au}$. These components were classify as precious metal containing category. Main metal elements in TV bare PCBs, PC bare PCBs and Relays are $\mathrm{Cu}$, followed by Tin and Lead, which are classify as $\mathrm{Cu}$ rich category. USB frame, CPU frame, Line interface frame contains $\mathrm{Fe}$ and $\mathrm{Al}$, which are classified as frames category. Besides, batteries should collected individually. The category suggestion is shown in Table 5 . Among these 4 categories, precious metal containing category and $\mathrm{Cu}$ rich category are suitable for ball milling treatment process. Detailed classification may need manual pre-processing and result in higher cost. However, researches have confirmed that automated processes involving shredding of items with PCBs inside cause PMs to be dispersed. Separation of fractions then results in significant PM losses by unintended co-separation. Manual isolation of PCBs achieves the highest bottom-line recovery rates, which justifies the costs (Charles et al., 2017).

\section{Conclusions}

The present study successfully developed an integrated MC process for valuable metals recovery from e-waste. Soluble metallic compounds were produces after treatment with dry ball milling and consequently benefit the subsequent leaching process. Based on the XRD, XPS results and thermodynamic parameters of the probable reactions, possible reaction pathways during ball milling were proposed. This process has the advantages of highly efficient and quick leaching speed. Remarkably, the process can avoid the use of nitric acid or mixture of nitric acid with hydrochloric acid 
or sulfuric acid, which is commonly used in the recovery of $\mathrm{Cu}, \mathrm{Ag}$ and $\mathrm{Pd}$, and consequently avoid the release of gaseous pollutants, such as $\mathrm{NO}_{2}$ or NO. Only some care must be taken in management of diluted acidic wastewaters and a small amount of ammoniacontaining wastewater. Therefore, it is an environmentally friendly method for recycling metals from e-wastes. Further work will be carried out to test the adaptation of MC process to different kinds of e-wastes, such as gold containing e-waste.

\section{Acknowledgements}

This work was supported by the National Natural Science Foundation of China - China $(51608517,21477151)$ and Shanghai Cooperative Centre for WEEE Recycling.

\section{Appendix A. Supplementary material}

Supplementary data associated with this article can be found, in the online version, at http://dx.doi.org/10.1016/j.wasman.2017.07. 029.

\section{References}

Akcil, A., Erust, C., Gahan, C.S., Ozgun, M., Sahin, M., Tuncuk, A., 2015. Precious meta recovery from waste printed circuit boards using cyanide and non-cyanide lixiviants - a review. Waste Manage. 45, 258-271.

Alzate, A., López, M.E., Serna, C., 2016. Recovery of gold from waste electrical and electronic equipment (WEEE) using ammonium persulfate. Waste Manage. 57, $113-120$.

Chagnes, A., Cote, G., Ekberg, C., Nilsson, M., Retegan, T., 2016. WEEE Recycling: Research, Development, and Policies. Elsevier.

Chai, L.-Y., Liang, Y.-J., Ke, Y., Min, X.-B., Tang, C.-J., Zhang, H.-J., Xie, X.-D., Yuan, C.-Y., 2013. Mechano-chemical sulfidization of zinc oxide by grinding with sulfur and reductive additives. Trans. Nonferr. Metal. Soc. 23, 1129-1138.

Chancerel, P., Meskers, C.E.M., Hagelüken, C., Rotter, V.S., 2009. Assessment of precious metal flows during preprocessing of waste electrical and electronic equipment. J. Ind. Ecol. 13, 791-810.

Charles, R.G., Douglas, P., Hallin, I.L., Matthews, I., Liversage, G., 2017. An investigation of trends in precious metal and copper content of RAM modules in WEEE: Implications for long term recycling potential. Waste Manage 60, 505-520.

Chawla, S.K., Sankarraman, N., Payer, J.H., 1992. Diagnostic spectra for Xps analysis of CU-O-S-H compounds. J. Electron Spectrosc. Relat. Phenom. 61, 1-18.

Cui, J., Zhang, L., 2008. Metallurgical recovery of metals from electronic waste: review. J. Hazard. Mater. 158, 228-256.

Ficeriová, J., Baláž, P., 2010. Leaching of gold from a mechanically and mechanochemically activated waste. Acta Montanistica Slovaca 15, 183.

Fu, Y., Chen, Q., He, M., Wan, Y., Sun, X., Xia, H., Wang, X., 2012. Copper ferritegraphene hybrid: a multifunctional heteroarchitecture for photocatalysis and energy storage. Ind. Eng. Chem. Res. 51, 11700-11709.

Garay, A.L., Pichon, A., James, S.L., 2007. Solvent-free synthesis of metal complexes. Chem. Soc. Rev. 36, 846-855.

Guo, X., Xiang, D., Duan, G., Mou, P., 2010. A review of mechanochemistry applications in waste management. Waste Manage. 30, 4-10.

Hartley, F.R., 2013. Chemistry of the Platinum Group Metals: Recent Developments. Elsevier.

Hasegawa, H., Rahman, I.M., Egawa, Y., Sawai, H., Begum, Z.A., Maki, T., Mizutani, S. 2013. Recovery of indium from end-of-life liquid-crystal display panels using aminopolycarboxylate chelants with the aid of mechanochemical treatment. Microchem. J. 106, 289-294.

Heegn, H., 1986. ScD. Theses, Research Institute of Mineral Processing of The Academy of Sciences of the GDR, Freiberg(in German).

Huang, A., Zhang, Z., Wang, N., Zhu, L., Zou, J., 2016. Green mechanochemical oxidative decomposition of powdery decabromodiphenyl ether with persulfate. J. Hazard. Mater. 302, 158-165.

Işıldar, A., van de Vossenberg, J., Rene, E.R., van Hullebusch, E.D., Lens, P.N., 2016. Two-step bioleaching of copper and gold from discarded printed circuit boards (PCB). Waste Managem 57, 149-157.

Jianmin, Y., 2010. A Handbook of Synthesis of Precious Metals Compounds and Complexes. Chemical Industry Press, Beijing.

Karwowska, E., Andrzejewska-Morzuch, D., Lebkowska, M., Tabernacka, A. Wojtkowska, M., Telepko, A., Konarzewska, A., 2014. Bioleaching of metals from printed circuit boards supported with surfactant-producing bacteria. J. Hazard. Mater. 264, 203-210.

Kaya, M., 2016. Recovery of metals and nonmetals from electronic waste by physical and chemical recycling processes. Waste Managem 57, 64-90.
Kim, E.-Y., Kim, M.-S., Lee, J.-C., Jeong, J., Pandey, B., 2011. Leaching kinetics of copper from waste printed circuit boards by electro-generated chlorine in $\mathrm{HCl}$ solution. Hydrometallurgy 107, 124-132.

Kragten, J., 1980. An evaluation of the stability constants of the chloro-complexes of palladium (II). Talanta 27, 375-377.

Kurmaev, E.Z., Fedorenko, V.V., Galakhov, V.R., Bartkowski, S., Uhlenbrock, S., Neumann, M., Slater, P.R., Greaves, C., Miyazaki, Y., 1996. Analysis of oxyanion $\left(\mathrm{BO}_{3}^{3-}, \mathrm{CO}_{3}^{2-}, \mathrm{SO}_{4}^{2-}, \mathrm{PO}_{4}^{3-}, \mathrm{SeO}_{4}^{4-}\right)$ substitution in $\mathrm{Y} 123$ compounds studied by X-ray photoelectron spectroscopy. J. Supercond. 9, 97-100.

Lindberg, B., Hamrin, K., Johansson, G., Gelius, U., Fahlman, A., Nordling, C., Siegbahn, K., 1970. Molecular spectroscopy by means of ESCA II. Sulfur compounds. Correlation of electron binding energy with structure. Phys. Scr. 1, 286-298.

Liu, T.-X., Li, X.-Z., Li, F.-B., 2008. AgNO $\mathrm{A}_{3}$-induced photocatalytic degradation of odorous methyl mercaptan in gaseous phase: mechanism of chemisorption and photocatalytic reaction. Environ. Sci. Technol. 42, 4540-4545.

Liu, X., Zhang, X., Zhang, K., Qi, C., 2016. Sodium persulfate-assisted mechanochemical degradation of tetrabromobisphenol A: Efficacy, products and pathway. Chemosphere 150, 551-558.

Mekki, A., Holland, D., McConville, C.F., 1997. X-ray photoelectron spectroscopy study of copper sodium silicate glass surfaces. J. Non-Cryst. Solids 215, 271282.

Mio, H., Lee, J., Nakagawa, T., Kano, J., Saito, F., 2001. Estimation of extraction rate of yttrium from fluorescent powder by ball milling. Mater. Trans. 42, 2460-2464.

Morf, L.S., Tremp, J., Gloor, R., Schuppisser, F., Stengele, M., Taverna, R., 2007. Metals, non-metals and PCB in electrical and electronic waste-Actual levels in Switzerland. Waste Manage. 27, 1306-1316.

Motozuka, S., Tagaya, M., Ogawa, N., Fukui, K., Nishikawa, M., Shiba, K., Uehara, T., Kobayashi, T., 2014. Effective preparation of graphite nanoparticles using mechanochemical solid-state reactions. Solid State Commun. 190, 28-32.

Nasser, A., Mingelgrin, U., 2012. Mechanochemistry: A review of surface reactions and environmental applications. Appl. Clay Sci. 67-68, 141-150.

Oguchi, M., Murakami, S., Sakanakura, H., Kida, A., Kameya, T., 2011. A preliminary categorization of end-of-life electrical and electronic equipment as secondary metal resources. Waste Manage, 2150-2160.

Ou, Z., Li, J., 2014. Synergism of mechanical activation and sulfurization to recover copper from waste printed circuit boards. RSC Adv. 4, 51970-51976.

Plescia, P., Gizzi, D., Benedetti, S., Camilucci, L., Fanizza, C., De Simone, P., Paglietti, F., 2003. Mechanochemical treatment to recycling asbestos-containing waste. Waste Manage. 23, 209-218.

Senanayake, G., 2012. Gold leaching by copper(II) in ammoniacal thiosulphate solutions in the presence of additives. Part I: A review of the effect of hard-soft and Lewis acid-base properties and interactions of ions. Hydrometallurgy 115 $1-20$.

Takacs, L., 2002. Self-sustaining reactions induced by ball milling. Prog Mater. Sci. 47, 355-414.

Takacs, L., 2009. Self-sustaining reactions induced by ball milling: An overview. Int. J. Self-Propag. High-Temp Synth. 18, 276-282.

Tan, Q., Li, J., 2015. Recycling metals from wastes: a novel application of mechanochemistry. Environ. Sci. Technol. 49, 5849-5861.

Tan, O. Li, J., Zeng, X., 2015. Rare earth elements recovery from waste fluorescent lamps: a review. Crit. Rev. Environ. Sci. Technol. 45, 749-776.

Tsuzuki, T., Ding, J., McCormick, P.G., 1997. Mechanochemical synthesis of ultrafine zinc sulfide particles. Physica B 239, 378-387.

Veit, H.M., Diehl, T., Salami, A., Rodrigues, J., Bernardes, A., Tenorio, J., 2005 Utilization of magnetic and electrostatic separation in the recycling of printed circuit boards scrap. Waste Manage. 25, 67-74.

Wang, M.-M., Zhang, C.-C., Zhang, F.-S., 2016. An environmental benign process for cobalt and lithium recovery from spent lithium-ion batteries by mechanochemical approach. Waste Manage. 51, 239-244.

Xiu, F.-R., Qi, Y., Zhang, F.-S., 2013. Recovery of metals from waste printed circuit boards by supercritical water pre-treatment combined with acid leaching process. Waste Manage. 33, 1251-1257.

Yu, X.-R., Liu, F., Wang, Z.-Y., Chen, Y., 1990. Auger parameters for sulfur-containing compounds using a mixed aluminum-silver excitation source. J. Electron Spectrosc. Relat. Phenom. 50, 159-166.

Yuan, W., Li, J., Zhang, Q., Saito, F., 2012. Innovated application of mechanical activation to separate lead from scrap cathode ray tube funnel glass. Environ. Sci. Technol. 46, 4109-4114.

Yuan, W.Y., Li, J.H., Zhang, Q.Q., Saito, F., Yang, B., 2013. A novel process utilizing mechanochemical sulfidization to remove lead from cathode ray tube funnel glass. J Air Waste Manage. 63, 418-423.

Zhang, K.L., Huang, J., Yu, G., Zhang, Q.W., Deng, S.B., Wang, B., 2013. Destruction of Perfluorooctane Sulfonate (PFOS) and Perfluorooctanoic Acid (PFOA) by Ball Milling. Environ. Sci. Technol. 47, 6471-6477.

Zhang, Z., Zhang, F.-S., 2013. Synthesis of cuprous chloride and simultaneous recovery of $\mathrm{Ag}$ and Pd from waste printed circuit boards. J. Hazard. Mater., 398404

Zhang, Z., Zhang, F.-S., 2014. Selective recovery of palladium from waste printed circuit boards by a novel non-acid process. J. Hazard. Mater. 279, 46-51.

Zhao, S., Peng, Y., 2012. The oxidation of copper sulfide minerals during grinding and their interactions with clay particles. Powder Technol. 230, 112-117.

Zhu, P., Chen, Y., Wang, L.Y., Zhou, M., Zhou, J., 2013. The separation of waste printed circuit board by dissolving bromine epoxy resin using organic solvent. Waste Manage. 33, 484-488. 